\title{
DA IMPORTÂNCIA DE SUBSTITUIR A EDUCAÇÃO FÍSICA DA ESCOLA POR ATIVIDADES FÍSICAS E/ OU ESPORTIVAS REALIZADAS EM ACADEMIAS, CLUBES, ESCOLINHAS*
}

\author{
Anegleyce T. Rodrigues, Fernando Mascarenhas, Rúbia-Mar Nunes \\ Pinto E Nivaldo ANTÔNIo David **
}

\section{A FUNÇÃO DA EDUCAÇÃO}

\begin{abstract}
Educação em seu sentido mais amplo deve ser compreendida como A um instrumento que deve possibilitar aos indivíduos - sujeitos sociais - a promoção e a ampliação das condições fundamentais para o exercício de sua cidadania, de sua função produtiva e de sua realização social.
\end{abstract}

Neste sentido, a educação escolar deve cumprir o papel de garantir a universalização do conhecimento a todos, visando preparar o indivíduo para a vida social, entendendo, inclusive, que preparar o indivíduo não significa dotá-lo de uma série de informações superficiais e descontextualizadas do lugar onde se realiza a sua experiência de vida, mas instrumentalizá-lo na formação de competências (técnicas, científicas, políticas, corporais, estéticas, éticas e sociais) que facilitem uma melhor compreensão e uma adequada intervenção junto à realidade social.

Deste modo, pensar sobre a educação é pensar sobre um bem social que se orienta por uma determinada visão de mundo e de homem, utilizando-se de objetivos, metodologias e técnicas pedagógicas para o seu fazer cotidiano, e que se estrutura, sobretudo, a partir de compromissos claramente definidos com a formação educativa, científica, cultural e social, tendo em conta o coletivo de indivíduos que interagem, num determinado contexto, em busca da melhoria de sua existência social.

\footnotetext{
* Parecer Encaminhado ao Conselho Estadual de Educação de Goiás.

***Professores da Faculdade de educação Física - UFG.
} 


\section{TAREFAS DA EDUCAÇÃO ESCOLAR}

É importante compreender que uma das principais características de educação escolar é a de representar uma atividade educativa e social que prima pela sistematização dos conhecimentos - sob a forma de conteúdos de ensino - a serem ensinados aos alunos, visando à apropriação do saber historicamente acumulado e dado como válido pela humanidade.

Outra característica importante da escola é a intencionalidade com que desenvolve e estrutura a sua ação pedagógica, procurando dar significados, tanto teóricos quanto práticos, ao que se ensina e para que serve a aprendizagem do aluno quando de sua aplicação prática no campo profissional, nas relações produtivas, na ação cultural e na sociedade.

Para a realização de seu fazer pedagógico, a educação escolar caracteriza-se, e de forma muito particular, como uma atividade que desenvolve e utiliza metodologias para transmissão dos conhecimentos, seja no sentido de buscar uma adequada forma de transmitir os conteúdos, como o de avaliar o grau de aprendizagem dos alunos no transcorrer da escolaridade.

Isto posto, é preciso entender que a escola, especialmente a de nossos dias, seja ela voltada para o ensino infantil quanto para o fundamental e o médio, modificou e ampliou ainda mais o seu campo de ação com a instituição de novas atribuições e exigências. Destaca-se, entre elas, a de procurar romper com visão de que sua função se resumia apenas em lidar, de forma restrita, com a sistematização do saber e com o ensino formal, passando a construir formas metodológicas que visam a estimular e/ou possibilitar ao aluno a apropriação de novos conhecimentos, dotando-o de métodos e técnicas que auxiliem a produzir ou reavaliar os conhecimentos dados como verdadeiros no âmbito da vida científica, cultural e social.

Assim, conclui-se que compete à escola a tarefa central de preparar e elevar o sujeito ao domínio de instrumentos científicos, culturais, profissionais, políticos, bem como de hábitos e valores, para que possa atuar construtivamente na vida social, o que significa, em outros termos, formar para o exercício da cidadania social.

Dentro desta perspectiva de formação para a cidadania, vamos deparar, portanto, com as orientações legais expressas pela LDB (Lei n ${ }^{\circ}$. 
9.394), com as Diretrizes Curriculares (CNE) para os ensinos infantil, fundamental e médio e com os Parâmetros Curriculares Nacionais estabelecidos pelo MEC para a educação escolar brasileira.

\section{O PROJETO PEDAGÓGICO DA ESCOLA E A EDUCAÇÃO FÍSICA}

A Lei de Diretrizes e Bases afirma que os currículos do ensino fundamental e médio devem ter uma base nacional comum a ser contemplada e uma parte diversificada em cada sistema de ensino e estabelecimento escolar, com base nas características regionais e locais da sociedade, da cultura, da economia e da clientela. Tais pressupostos reforçam ainda mais a idéia da importância e da necessidade de se trabalhar com a educação escolar a partir da integração das várias áreas de conhecimentos no sentido de garantir uma formação mais abrangente ao aluno, no que diz respeito aos conhecimentos considerados clássicos e àqueles que se relacionam aos elementos concretos da realidade social e política do País.

Com relação à educação física, a LDB aponta, em suas diretrizes, que a sua realização e execução nos ensinos fundamental e médio deverão ser integradas à proposta pedagógica da escola como um componente curricular obrigatório da educação básica. A educação física deve ajustarse às faixas etárias e às condições da população escolar, sendo, todavia, facultativa (aos alunos e não às instituições de ensino) nos cursos noturnos.

Estas novas orientações legais, que diferem em sua natureza e tratamento das normas educacionais até então desenvolvidas na escola, reforçam a idéia de que os componentes curriculares devem ser tratados, de forma articulada e integrada, interdisciplinarmente no conjunto da ação educativa e pedagógica no ambiente educacional.

Quanto aos PCNs, a educação física é a área de conhecimento que introduz e integra os alunos na cultura corporal de movimentos, visando ao lazer, à expressão de sentimentos, afetos e emoções e à manutenção da melhoria da saúde - tudo isso devidamente integrado ao projeto da escola.

Destacamos, a seguir, os objetivos previstos para serem alcançados no final da escolarização: 
- Participar de atividades corporais, estabelecendo relações equilibradas e construtivas com os outros, reconhecendo e respeitando as características físicas e de desempenho de si próprio e dos outros, sem discriminação de características pessoais, físicas, sexuais ou sociais.

- Conhecer, valorizar, respeitar e desfrutar da pluralidade de manifestações da cultura corporal no Brasil e no mundo, percebendo-as como recursos valiosos para a integração entre pessoas e entre diferentes grupos sociais e étnicos.

- Solucionar problemas de ordem corporal em diferentes contextos, regulando e dosando o esforço de forma compatível com as possibilidades, considerando que o aperfeiçoamento e o desenvolvimento das competências corporais decorrem de perseverança e regularidade e devem ocorrer de modo saudável e equilibrado.

- Conhecer a diversidade de padrões de saúde, beleza e desempenho que existe nos diferentes grupos sociais, compreendendo a sua inserção dentro da cultura em que são produzidos, analisando criticamente os padrões divulgados pela mídia e evitando o consumismo e o preconceito.

- Conhecer, organizar e interferir no espaço de forma autônoma, bem como reivindicar locais adequados para promover atividades corporais de lazer, reconhecendo-as como uma necessidade do ser humano e um direito do cidadão a uma melhor qualidade de vida.

Para que sejam concretizadas tais perspectivas, foram definidos alguns critérios para a seleção e definição dos conteúdos, dentre os quais destacamos: a relevância social, as características dos alunos e a especificidade do conhecimento da área.

Nestes Parâmetros são indicados, além dos temas transversais, três blocos de conteúdos de ensino, que deverão centralizar o fazer pedagógico: 1) os esportes, os jogos, as lutas e as ginásticas; 2) o conhecimento sobre o corpo; 3 ) as atividades rítmicas e expressivas. Estes blocos deverão ser tratados de forma integrada entre as demais áreas (conteúdos) escolares e nos diversos ciclos de ensino e aprendizagem social preconizados pela LDB.

Do exposto acima, pode-se verificar um explícito rompimento com o tratamento tradicionalmente dado aos alunos que privilegiavam a aptidão física, o rendimento e a exclusão das atividades pela sua incapacidade de apropriar-se a performances esportivas. Este novo modelo adota, como eixo de sua ação pedagógica, uma perspectiva metodológica de 
ensino e aprendizagem centrada no princípio da inclusão (inclusive do portador de necessidades especiais), com vistas ao desenvolvimento da autonomia, da cooperação e da participação social, reafirmando, assim, os princípios e valores democráticos. Desta forma busca-se garantir a todos a possibilidade de conhecer e usufruir dos jogos, esportes, danças, lutas e ginásticas em benefício do exercício crítico e da cidadania.

\section{A ESCOLA E AS INTER-RELAÇÕES SOCIABILIZADORAS NA FORMAÇÃO EDUCATIVA}

Diferentemente de outros tempos, as interações que ocorrem na escola e que assumem dimensões relevantes no processo de ensino e aprendizagem estão sendo focalizadas hoje como elementos estruturantes e de significativa importância no contexto da formação escolar. Trata-se, em especial, da relação professor-aluno que não deve mais ser compreendida como uma relação unilateral e autoritária ou, mesmo, de uma atitude de descaso e passividade do professor para com o aluno, mas como uma relação que se estabelece entre ambos, mediada pelo diálogo, pelo respeito e pela diretividade educativa, procurando alcançar os objetivos estabelecidos pela escola, pelo aluno e pelas exigências derivadas do contexto sociocultural.

Falar de interações entre professores e alunos é o mesmo que discorrer sobre processos, procedimentos e metodologias aplicados ao contexto educativo escolar, pois a qualidade e a forma em que se dão estas relações certamente estarão influindo ou definindo tanto o sentido quanto a própria qualidade da educação desenvolvida na escola.

\section{NOSSO POSICIONAMENTO}

Nesta síntese tornou-se possível identificar o papel, a função, as atribuições da educação escolar na formação educativa; a forma de organização da atividade pedagógica (estrutura, sistemas e métodos) na escola; e as contribuições históricas oferecidas pelos conteúdos da Educação Física na formação da criança e do adolescente. Some-se a isso a obrigatoriedade instituída pela LDB e pelo MEC, que garante a todo aluno o direito de se beneficiar destes conteúdos pedagógicos, científicos e culturais, legitimando, assim, os conhecimentos e ratificando a impor- 
tância da cultura corporal no âmbito da formação escolar. Cabe-nos reafirmar que o procedimento de substituir esta prática por outra seria, no mínimo, um absurdo metodológico, uma atitude aética e um tremendo equívoco por parte dos professores de educação física, dos diretores e coordenadores pedagógicos.

Além da natureza do trabalho escolar, os conteúdos, as metodologias e as finalidades sociais da educação física já seriam suficientes para justificá-la como uma prática especial no campo das demais práticas sociais. Entendemos que tais iniciativas são procedimentos impróprios e ambíguos, uma vez que a escola não é a família e nem pode substituí-la, não é a Igreja e nem pode substituí-la, não é o clube esportivo e nem pode substituí-lo e nem é a academia de ginástica, não podendo, do mesmo modo, também substituí-la. Tal tentativa, além de descaracterizar a escola de sua função educativa e social, se torna, no melhor dos juízos, uma ação ilegal uma vez que fere as determinações constitucionais e as orientações do Estado que tenta implementar - de forma prática, objetiva e coletiva - os conteúdos que representam o espírito do legislador/nação que busca, em seu projeto de emancipação social, a melhoria da qualidade de vida e a formação de cidadãos conscientes e reflexivos.

Substituir os conteúdos e procedimentos desenvolvidos pela educação física escolar por outras atividades é perder a centralidade da formação educativa e prestigiar conteúdos restritos, exclusivistas e particulares. É, inclusive, expor os alunos a experiências "educativas" que apontam para rumos totalmente contrários ao que preconizam a educação, a escola e a própria educação física. Estas são as atividades desenvolvidas por várias academias, clubes esportivos, entidades recreativas e/ou instituições de natureza privada orientadas por finalidades lucrativas.

Com esta crítica, não estamos depreciando estas atividades extraclasses ou extra-escolares, pois achamos que são válidas e podem enriquecer e acrescentar outros conhecimentos à vida da pessoa na área do lazer e da saúde. Estas, inclusive, devem ser prestigiadas e estimuladas pelos pais, pela escola e pela própria educação física (um dos campos de atuação profissional). É preciso também deixar claro que os seus objetivos diferenciam da proposta da escola, não integram os conhecimentos desenvolvidos pelo homem/sociedade aos demais conhecimentos científicos e nem estão articulados aos verdadeiros fins da educação e da formação da cidadania social. 